\title{
S.P conversion at the base of the crust
}

\author{
M. Batth - R. Stefaisson
}

Ricevuto il 7 Marzo 1966

\begin{abstract}
Summary. - The long-period seismic records at Umeå (Sweden) of an intermediate-depth earthquake in Burma on 27 February, 1964, exhibit an exceptionally clear case of $S \cdot P$ conversion at the Mohorovicić discontinuity. The records are examined from various points of view (arrival times, amplitude ratios, particle motions) and comparisons are made for each test between observations and theory. General aspects of mode conversions at the base of the crust are discussed, both their importance and why they are so seldom observed.
\end{abstract}

Riassunto. - Il terremoto di Burma del 27 Febbraio 1964 (profondità intermedia), registrato sul lungo periodo della stazione di Umeå (Svezia), mostra un caso eccezionalmente chiaro di conversione di onde S.P alla discontinuità di Mohorovicic. I sismogrammi sono stati esaminati da vari punti di vista (tempi di arrivo, rapporti fra le ampiezze, movimenti di particelle...) e per ognuno di essi è stato fatto il confronto fra dati di osservazione e teoria.

Vengono discussi, inoltre, gli aspetti generali del modo di conversione alla base della crosta, insieme alla loro importanza ed al perché possono osservarsi tanto raramente.

\section{INTRODUCTION.}

For seismic waves which do not penetrate deeper than the mantle (that is, up to about $103^{\circ}$ distance), the most pronounced internal discontinuity encountered during the propagation is the base of the crust, the Mohorovicic discontinuity. At this surface, not only reflections and refractions occur, but also conversions of $S$ to $P$ and of $P$ to $S$. Such phenomena may occur both near the hypocenter and near the station as well as in between (for reflected waves). Due to the relative proximity of the Moho to the Earth's surface, waves deriving from Moho arrive only within a few seconds from the parent waves. This naturally often makes it difficult to discover such waves. They may be 
immersed in already existing motion, as e.g. for $P-S$ converted waves which arrive a few seconds after $P$. The $S-P$ converted waves, on the other hand, arrive before the true $S$ and may therefore be easier to discover. They are also of great significance as they may give rise to too early, false readings of $S$.

The relative difficulty to establish reliably the existence of Mohoderived waves is the probable explanation why the seismological literature contains only some scattered information on this point. Reflections against Moho from below will give rise to too early arrivals (as sometimes observed for $P P$ ). Such reflections were studied by Choudhury (1958) and Treskov (1961) and were used for estimating crustal thickness at the reflection point. Reflections against Moho from above have been observed repeatedly in seismic field investigations (see e.g. Bath and Tryggvason, 1962). PS converted waves were reviewed by Cook, Algermissen and Costain (1962) and $S P$ converted waves were studied by Pachadzhanova (1962). Additional references can be found in the papers mentioned. Also more complicated wave paths, involving multiple passages between Moho and the Earth's surface, have been reported in the literature (see e.g. Jun-Ju, 1965).

The present paper explores records of $S P$ converted waves obtained at Umea (Sweden) from an intermediate-depth earthquake in Burma. Of the publications mentioned, it has the closest relations to the paper by Pachadzhanova (1962).

It will be convenient to have some notation for Moho-derived waves and we are suggesting the following scheme, which is constructed in conformity with existing wave notations:

1) $P s$ for $P S$ converted waves, and $S p$ for $S P$ converted waves (conforming to the rule that small letters, $s$ and $p$, are used for waves which propagate only upwards).

2) $P m P, P m p$ and $p m P$ for reflected waves (in conformity with PcP; this notation was suggested by Choudhury, 1958). $m$ can be used to denote reflection against Moho from either side.

3) More complicated wave paths can then be easily described in the same system. For example, $S p P m p$ is an incident $S$ against Moho from below, which is converted into $P$, then reflected as $P$ against the surface and after that against Moho, before it finally arrives at the surface.

4) In case of more than one layer, indices $1,2,3, \ldots$ referring to the respective layers, should be added to the symbols. 


\section{OBSERVATIONAL DATA.}

U.S. Coast and Geodetic Survey reports the following data for the investigated earthquake:

Date and origin time: 27 February, $1964,15^{\mathrm{h}} 10^{\mathrm{m}} 48^{\mathrm{s}} 8$ GMT.

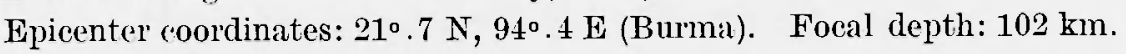
Magnitude (Uppsala, Kiruna): 6.5.

Recording station Umea (Sweden): $63^{\circ} 48^{\prime} .9 \mathrm{~N}, 20^{\circ} 14^{\prime} .2 \mathrm{E}$. Instruments: long-period standardized Press-Ewing seismographs $\left(T_{0}=\right.$ $\left.15 \mathrm{sec}, T_{g}=100 \mathrm{sec}\right)$.

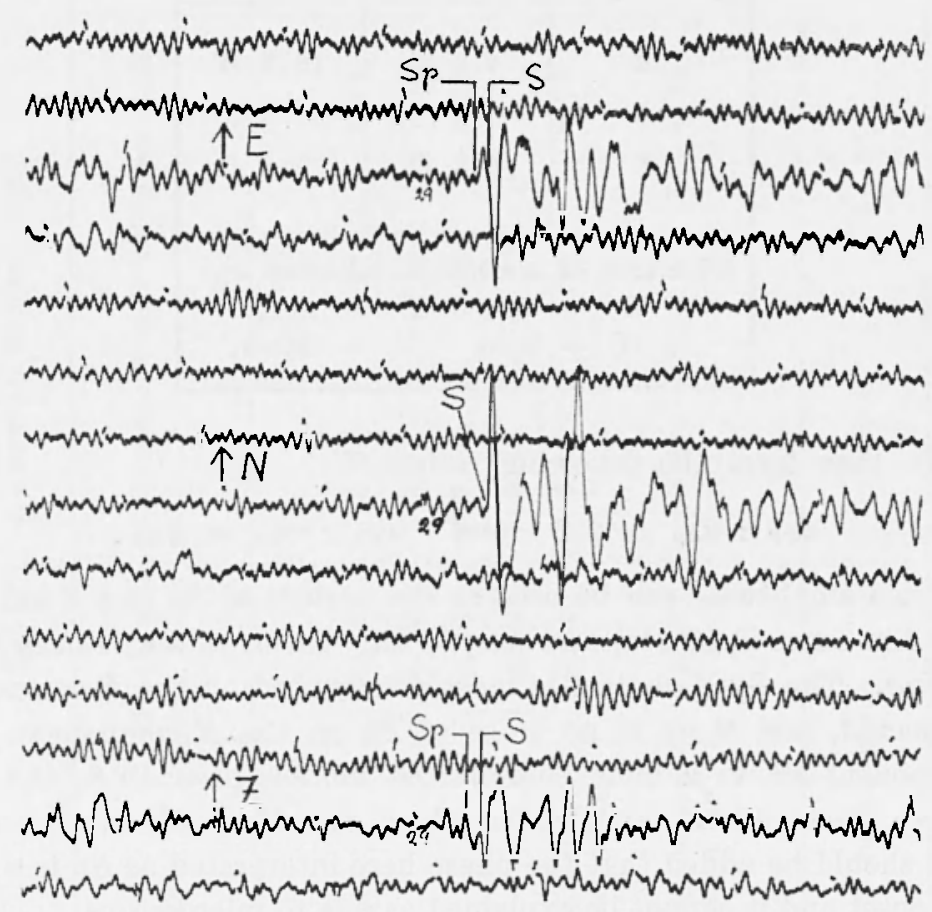

Fig. 1 -- $S$-wave group recorted by Umea long-period seismographs from Burma earthquake 27 February, 1964. Time increases from left to right and there is one minute between each time mark.

Epicentral distance: 63०.8. Epicenter azimuth at the station: $94^{\circ}$ (i.e. only $4^{\circ}$ south of east).

Time reading (see records in Fig. 1) for $S$ (actually $S p$ ) on $E$ :

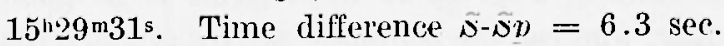


Amplitude readings are summarized in Table I. Resolving the motion into $S \nabla, S H$ and $S p$ components we find $(u=$ horizontal component, $w$ - vertical component):

$$
\begin{aligned}
& u_{S V}=17.8 \mathrm{~mm} W D \text { (i.e. directed west and down), } \\
& u_{S H}=20.7 \mathrm{~mm} N E \text { (i.e. directed north and east), } \\
& u_{S p}=4.2 \mathrm{~mm} E D \quad \text { (i.e. directed east and down). }
\end{aligned}
$$

Table I - Amplitude readings (mm trace amplitude)

\begin{tabular}{|c|c|c|}
\hline Component & $S p$ & $S$ \\
\hline$E$ & $4.2 E$ & $16.3 \mathrm{~W}$ \\
$N$ & - & $21.9 \mathrm{~N}$ \\
$Z$ & $2.8 \mathrm{D}$ & $5.6 \mathrm{D}$ \\
& & \\
\hline Direction of motion is indicated by: \\
$E=$ east $\quad N=$ north \\
$W=$ west $\quad D=$ down. \\
\hline
\end{tabular}

We then form the following ratios:

$$
u_{S V}: u_{S D}=4.2 \text { and } w_{S V}: w_{S p}=2.0 \text {. }
$$

Trace amplitudes can be used as the periods of $S p$ and $S$ are practically the same $(8-10 \mathrm{sec})$ and we use only ratios of amplitudes in the following. The $S p$ - $S$ doublet is most pronounced on the $E$-component, as expected, and there is no trace of $S p$ on the $N$-component. The $Z$-component shows a more complicated motion prior to $S$, and on $Z$ we have measured the amplitudes which coincide with $E$.

It should be added that the phase here interpreted as $S p$ is a significant onset and it cannot be explained as due to microseisms.

\section{ARRIVAL TIMES.}

a) - Absolute arrival times. The Jeffreys-Bullen (1940) tables give a total travel time for $S$ of $18 \mathrm{~min} 48.7 \mathrm{sec}$ for the given focal data. This means a computed arrival time of $S$ at $15^{\mathrm{h}} 29^{\mathrm{m}} 37^{\mathrm{s}} 5$. This is in good agreement with the $S$-reading, whereas the $S p$-phase arrives about 6 sec 
Table II - Crustal models used.

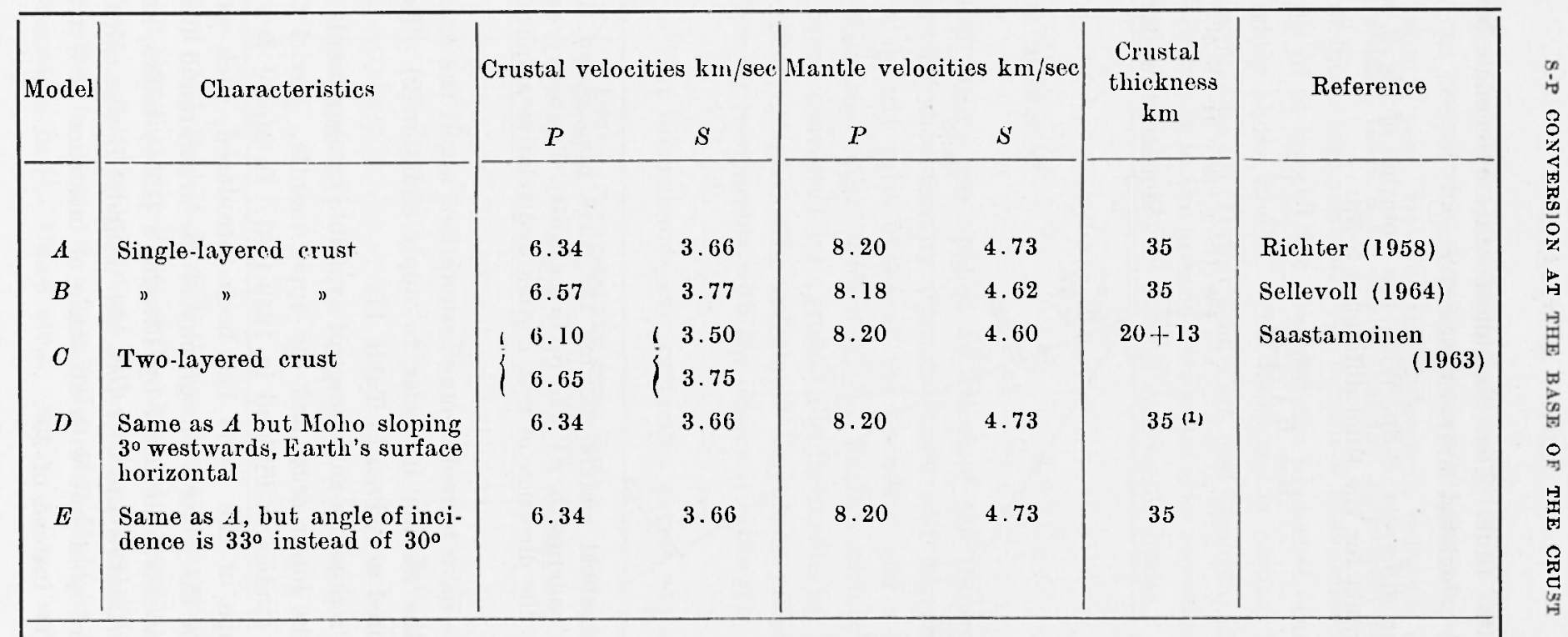

(1) Vertically beneath the station. 
earlier than this time. There is almost exact agrement between the observed and calculated arrival times of $P$.

b) - Time difference $S-S p$. With the notation of Fig. 2, we get the following formula for the time difference $S-S p$ :

$$
\Delta t=H\left(\frac{\cos i^{\prime}{ }_{S}}{V^{\prime}{ }_{S}}-\frac{\cos i^{\prime}{ }_{P}}{V_{P}^{\prime}}\right)
$$

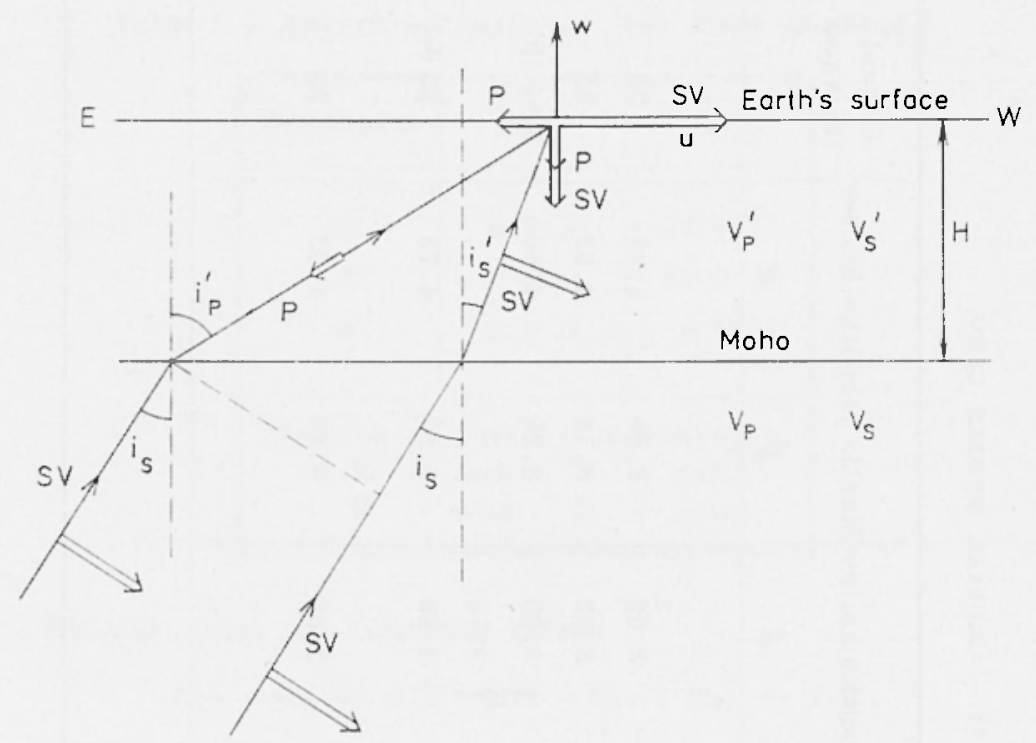

Fig. 2 - Schematical picture showing the wave propagation (incident $S$ at Moho from underneath, $S V$ and $S p$ in the crust). 'The heavy, open arrows indicate the direction of first motion and relative amplitudes.

Obviously, we have to make some assumptions about the crustal structure under the station in order to apply equation [2]. The models which were used are given in Table II.

Model $B$ represents an average of available measurements in Fennoscandia for the lower crust and the upper mantle. Model $C$ is based on explosion studies in Finland in 1959-1961. In Model $D$ a moderate westward slope of the Moho has been introduced, such as could be expected from the general topography of the area around Umea. The angles of incidence, calculated by Ritsema's (1958) tables, are subject to some uncertainties and therefore also a Model $E$ was calculated, the same structure as $A$ but with an angle of incidence of $S$ from below to Moho of $33^{\circ}$ instead of $30^{\circ}$. 
The calculated time difterences $S-S p$ are given in Table III, which also gives the crustal thicknesses necessary to give the observed time difference of 6.3 sec. Despite the differences between observed and calculated values, there is no doubt that the agreement is satisfactory, taking error limits into account. The measured time difference of $6.3 \mathrm{sec}$ has an error of at least $\pm \mathbf{0 . 4}$ sec, and the requested crustal thickness is only slightly above $40 \mathrm{~km}$. This thickness is verified by phase velocities of surface waves (Tryggvason, 1961, and Crampin, 1964). Taking also the uncertainty in the assumed velocities into account, we can safely say that our observation falls within reasonable limits.

\section{AMPLITUde Ratios.}

Classical theory was applied to calculate the transmission across the Mohorovicic discontinuity (Costain, Cook and Algermissen, 1963), assuming a density ratio of 0.8 at the boundary and a Poisson ratio of 0.25 . The amplitudes incident at the Earth's surface calculated in this way, were converted into ground displacements by means of Gutenberg's (1914) graphs. The calculated amplitude ratios (Table III) are then directly comparable with the observed ratios [1].

Table III - 'Time differences and ampeltude ratios Hor given models.

\begin{tabular}{|c|c|c|c|c|}
\hline \multirow{2}{*}{ Model } & \multirow{2}{*}{$\begin{array}{c}\text { Time } \\
\text { difference } \\
S-S p \\
\text { sec }\end{array}$} & \multirow{2}{*}{$\begin{array}{l}\text { Crustal thicliness (km) } \\
\text { for time difference } \\
S-S p=6.3 \text { sec }\end{array}$} & \multicolumn{2}{|c|}{ Anjplitude ratios } \\
\hline & & & $u_{S V}: u_{S p}$ & $w_{S V}: w_{S p}$ \\
\hline$A$ & 4.8 & 46 & 5.3 & 2.8 \\
\hline$B$ & 4.7 & 47 & 5.9 & 3.4 \\
\hline$C$ & 4.7 & & & \\
\hline$D$ & 4.8 & 46 & 4.5 & 2.3 \\
\hline$E$ & 4.9 & 45 & 4.3 & 2.8 \\
\hline
\end{tabular}

We find that Models $D$ and $E$ give the best agreement. Taking into account that the error limits of the observed ratios [1] can be estimated as about \pm 0.4 , the agreement with Models $D$ and $E$ is satisfactory. This may even be taken as a suggestion that Moho is in fact gently sloping westwards in the Umeâ area. 


\section{Particle Motion.}

a) - Direction of first motion. With common notations (see Båth, 1961) we have:

$$
u=\frac{\partial \Phi}{\partial x}-\frac{\partial \psi}{\partial z} ; \quad w=\frac{\partial \Phi}{\partial z}+\frac{\partial y}{\partial x}
$$

with

$$
\left.\begin{array}{l}
\psi=B \exp [i k(x+\beta z-\omega t)]+B_{1} \exp [i k(x-\beta z-\omega t)] \\
\psi^{\prime}=B^{\prime} \exp \left[i k\left(x+\beta^{\prime} z-\omega t\right)\right] \\
\Phi=A_{1} \exp [i k(x-\alpha z-\omega t)] \\
\Phi^{\prime}=A^{\prime} \exp [i k(x+\alpha z-\omega t)] .
\end{array}\right\}
$$

This gives the displacement in the incident $S V$-wave:

$$
\begin{aligned}
& u=-B i k \beta \exp [i k(x+\beta z-\omega t)] \\
& w=B i k \exp [i k(x+\beta z-\omega t)],
\end{aligned}
$$

in the transmitted $S V$-wave:

$$
\begin{aligned}
& u=-B^{\prime} i k \beta^{\prime} \exp \left[i k\left(x+\beta^{\prime} z-\omega t\right)\right] \\
& w=B^{\prime} i k \quad \exp \left[i k\left(x+\beta^{\prime} z-\omega t\right)\right],
\end{aligned}
$$

and in the transmitted $P$-wave $(S p)$ :

$$
\begin{array}{ll}
u=A^{\prime} i k & \exp \left[i k\left(x+\alpha^{\prime} z-\omega t\right)\right] \\
w=A^{\prime} i k \alpha & \exp \left[i k\left(x+\alpha^{\prime} z-\omega t\right)\right] .
\end{array}
$$

If we choose $B<0$, we have for the incident $S V$ that $u>0, w<0$, and for the transmitted $S V$ that $u>0, w<0$, and for the transmitted $P(S p)$ that $u<0, w<0$, because the ratios $B^{\prime} \mid B$ and $A^{\prime} / B$ are real and positive $\left(B^{\prime} / B=+0.90\right.$ and $A^{\prime} / B=+0.29$ according to Bath, 1961, table 3 , for $e=60^{\circ}$ ). These theoretical displacements are shown in Fig. 2 and they agree with the observations (Fig. 1). The fact that the first motion of $S p$ is opposite to that of $S V$ on the horizontal $(E)$ component, certainly facilitates its discovery, as distinct from the vertical component where $S p$ and $S V$ have the same sign.

b) - Total particle motion. We have so far been considering only the first onsets of the respective waves. Examining the entire particle motion we find that it is nearly linear both for $S p$ and for $S$, and that 
the motions of both waves agree closely with theoretically expected motions (assuming Model $A$ ). The minor deviations can be explained partly by reading difficulties, especially of $S p$ on the vertical component, partly by inaccuracies in the angles of incidence. Anyway, there is no doukt that $S p$ is a longitudinal wave related to $S V$ as expected from theory.

\section{DISCUSSION.}

Considering both the error limits in the observations and inevitable uncertainties in the theoretical models, we conclude that the interpretation of the $S p$-phase is convincing. This is the simplest interpretation, and as it has proven successful there is no need for investigation of more complicated wave propagations. Moreover, comparisons of observations and theoretical models suggest a crustal thickness of about 40-45 km in the Umea area, with the Mohorovicic discontinuity possibly sloping gently westwards.

It is a justified question why this phenomenon is observed so seldom. A correct statement would probably be to say that it exists much more frequently than generally realized, but it is only seldom that very clear cases are observed. There are a number of factors which contribute to this effect:

1) It is advantageous for discovery that the direction to the epicenter coincides with one of the cardinal directions, as otherwise any earlier wave will show up on both $E$ and $N$ components and will easily escape detection.

2) It should show up on the $Z$-component independent of azimuth, but $Z$ is usually bad for the $S$-wave group, and $S$ is generally read from the horizontal components.

3) Certain angles of incidence at Moho from below are more favourable for $S-P$ conversion than others. This means that certain distances in combination with certain slopes of the Moho discontinuity are more favourable than others (see Bath, 1961).

4) The ratios of ground displacements (i.e. corresponding to recorded displacements) to incident amplitudes vary considerably with the angles of incidence at the surface (Gutenberg, 1944, Fig. 3). In our case we are close to optimum conditions, but only smaller changes 
in the angles of incidence will entail considerable changes in the recorded amplitudes.

5) A substantial $S V$-component radiated in the direction of the recording station is needed (this means a certain restriction on the focal mechanism).

6) The microseismic noise level should not be too high, as otherwise a small $S p$ may be lost or diffeult to discover reliably.

7) Two sharp onsets $(S p$ and $S$ ) are required in clear cases, but in most cases $S$-phases are more blunt than $P$-phases and even if a multiplicity exists in $S$ this can often not be established with full certainty.

A combination of the factors mentioned is probably enough to explain why clear cases are observed so seldom.

Press-Ewing seismographs are also operated at Uppsala, but in the ease studied here they do not exhibit the Sp-phase. This could partly be due to smaller magnification at Uppsala than at Umea, partly to unfavourable conditions at Moho. Also, the phenomenon does not show up on the Umea short-period records, as the periods $(8-10 \mathrm{sec})$ are too long for these instruments.

Other cases of $S p$ have been observed at our stations, though less clear than the present one. Several of the aftershocks of the Alaska earthquake on 28 March, 1964, gave $S p$-phases on the $N$-components at Uppsala, Kiruna and Umea. This was especially the case for the aftershocks on 3 April (22 3342.2 ), and + April (17 $46^{\mathrm{m}} 08^{\mathrm{s}} .6$ and $\left.22^{\mathrm{h}} 16^{\mathrm{m}} 54^{\mathrm{s}} .5\right)$, 1964.

Reliable readings of $S$ are of basic importance for our knowledge about the Earth's interior, in calculations of transverse wave velocities, focal mechanism studies and for the interpretation of surface wave observations. Next to $P$ and $p P$ it is no doubt the most important phase in a seismic record. In a more detailed analysis it is then necessary to take the possible existence of $S p$ into account. $S p$ is more troublesome for accurate $S$-readings than $P s$ is for $P$-readings, as $P s$ arrives after $P$, but may disturb $p P$.

It is frequently found in routine measurements that the arrival of $S$ differs a few seconds between the two horizontal components. It is then customary to consider the earlier arrival as the true $S$ and to report only this onset in bulletins. However, it is obvious from this paper that such a procedure may often be incorrect (the earlier arrival may be $S p$ ). In order to decide the question in any individual case, it is necessary to apply criteria such as those used here. 
The time differences $P s-P$ and $S p$-S have sometimes been used for calculation of crustal thicknesses, but for higher accuracy this necessarily supposes that crustal velocities are well known.

\section{ACKNOWLEDGEMENT.}

One of us (R.S.) would like to express his gratitude to the Icelandic: Science Foundation for a scholarship enabling him to do this research at the Seismological Institute, Uppsala, Sweden.

Seismological Institute, Uppsala, Sweden.

March, 1966.

\section{REFERENCES}

B\&ті M., Polarization of transverse seismic waves. "Geophys. Jour. Roy. Astr. Soc. ", 4, 106-123, (1961).

B \&th M. and Tryggvason E., Deep seismic reflection experiments at Kiruna. "Geofis. pura e appl. », 51, 79-90, (1962).

Choudhury M. A., Élude des ondes sćismiques dans quelques tremblements de terre profonds de l'Hindou-Kouch. "Ann. Géophys. ", 14, 31-75, (1958).

Cook K.L., Algermissen S.T. and Costain J.K., The status of PS converted waves in cruslal studies. "Jour. Geophys. Res. ", 67, 4769-4778, (1962).

Costain J.K., Cook K.L. and Algermissen S.T., Amplitude, energy, and phase angles of plane $S Y$ waves and their application to earth crusial studies. "Bull. Seism. Soc. Amer. ", 53, 1039-1074, (1963).

Crampin S., Higher modes of seismic surface waves: Phase velocities across Scandinavia. "Jour. Geophys. Res.", 69, 4801-4811, (1964).

Gutenberg B., Energy ratio of reflected and refracted seismic waves. "Bull. Seism. Soc. Amer. ", 34, 85-102, (1944).

Jeffreys H. and Bullen K. E., Seismological Tables. "Brit. Assoc. Adv. Sci. ", 48 pp., (1940).

PaChadzhaxova G.N., Study of transformed waves SP type during deep Aghan earthquales (in Russian). Akad. nauk. Tadzkih SSR, Dushanbe, Trudy, 10, 10s-124, (1962).

Riciter C. F., Elementary Seismology. W. H. Freeman and Co., San Francisco, 768 pp., (1958).

RITSEma A.R., (i, A)-curves for bodily seismic waves of any focal depth. "Lembaga Meteor. dan Geofis.", Djakarta, Verhandel, 54, 10 pp., (1958). 
SaAstamoinen P., Travel times for a crustal model in Finland. Publ. Inst. Seism. Helsinki, 58, (1963).

Sellevoll M. A., A publications summary on crustal and upper mantle structure in Fennoscandia, Iceland and the Norwegian Sea. VESIAC Rep. 4410-75-X, 111-125, (1964).

Treskov A. A., On teleseismic determinations of the Earth's crust thickness. Publ. Bur. Centr. Seism. Int., A 22, 33-39, (1961).

Tryggrasox E., Crustal thickness in Fennoscandia from phase velocities of Rayleigh waves. "Annali di Geofisica ", 14, 267-293, (1961).

Yus-Yu D., SP' phases and the crustal thickness of China (in Chinese). "Acta Geophys. Sinica », 14, 168-172, (1965). 